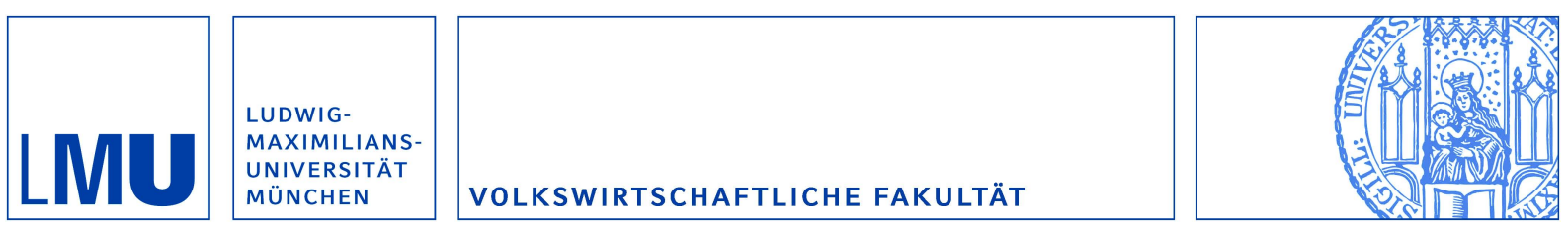

Haufler, Andreas und Mardan, Mohammed:

Cross-border loss offset can fuel tax competition

Munich Discussion Paper No. 2013-2

Department of Economics

University of Munich

Volkswirtschaftliche Fakultät

Ludwig-Maximilians-Universität München

Online at https://doi.org/10.5282/ubm/epub. 14362 


\title{
Cross-border loss offset can fuel tax competition*
}

\author{
Andreas Haufler ${ }^{\dagger} \quad$ Mohammed Mardan ${ }^{\ddagger}$ \\ University of Munich and CESifo University of Munich
}

January 2013

\begin{abstract}
Following recent court rulings, cross-border loss compensation for multinational firms will likely be introduced, at least in Europe. This paper analyzes the effects of introducing a coordinated cross-border tax relief in a setting where multinational firms choose the size of a risky investment and host countries endogenously choose tax rates. We show that coordinated cross-border loss compensation is likely to intensify tax competition when, following current international practice, the parent firm's home country bases the tax rebate for a loss-making subsidiary on its own tax rate. In equilibrium, tax revenue losses will then be even higher than is implied by the direct effect of the reform. In contrast, tax competition will be mitigated when the home country bases its loss relief on the tax rate in the subsidiary's host country.
\end{abstract}

Keywords: cross-border loss relief, tax competition, profit shifting

JEL Classification: H32, F23, H25

*Previous versions of this paper were presented at the Oxford University Centre of Business Taxation and at the Annual Congresses of the European Economic Association in Malaga, the International Institute of Public Finance in Dresden, and the German Economic Association in Göttingen. We thank Miguel Almunia, Mike Devereux, Clemens Fuest, Marcel Gérard, Dominika Langenmayr, Ben Lockwood and Kazuki Onji for helpful comments.

†Seminar for Economic Policy, Akademiestr. 1/II, D-80799 Munich, Germany. Phone: +49-89-21803858, fax: +49-89-2180-6296, e-mail: Andreas.Haufler@lrz.uni-muenchen.de

$\ddagger$ Seminar for Economic Policy, Akademiestr. 1/II, D-80799 Munich, Germany. Phone: +49-89-21803303, fax: +49-89-2180-6296, e-mail: Mohammed.Mardan@lrz.uni-muenchen.de 


\section{Introduction}

Tax systems around the world include a fundamental asymmetry in the treatment of positive and negative corporate incomes. Whereas positive profits are immediately taxed, the tax value of a loss is not refunded when the loss is incurred, but it can only be offset against positive incomes. This can either occur over time, usually in the form of tax loss carryforwards, or by setting off losses in one business line against positive profits in others within the same company or corporate group. However, in many cases firms are unable to use these loss offset opportunities. This asymmetry has long been known to cause important, negative effects on the investment and risk-taking decisions of firms (Altshuler and Auerbach, 1990; Devereux et al., 1994). Moreover, recent studies for the United States (Auerbach, 2007) and Europe (Fuest et al., 2007) show that the problem of unused tax losses is quantitatively a highly important one. ${ }^{1}$

In an international tax setting, there is another fundamental asymmetry. The national tax laws of most countries include provisions of 'group taxation' that allow losses in one entity of a corporate group to be offset against the profits made by another, legally independent entity of the same group. This provision, however, applies only when the parent and the subsidiary are resident companies of the same tax jurisdiction. In contrast, a cross-border loss offset between entities of a multinational corporation that reside in different countries is possible only in exceptional cases. $^{2}$

The different loss offset rules for multinational as compared to national corporate groups constitute an obvious discrimination against international investments. This is a particularly important issue in the European Union, as it seems to run counter to the freedom of establishment in the internal market. In 2005, a ruling of the European Court of Justice (ECJ) in the case of the U.K. based trade firm Marks and Spencer has therefore received widespread attention. In this case the ECJ decided that a parent company should not be prevented from deducting the losses of its subsidiary in another EU member state, if all loss offset possibilities in the host country of the subsidiary have been exhausted and the losses in the host country are therefore 'final losses'. ${ }^{3}$

\footnotetext{
${ }^{1}$ Auerbach (2007, Table 4), for example, documents that U.S. corporations reported annual losses of 350-400 billion USD in aggregate in each of the years 2001-2003, representing roughly two thirds of positive corporate profits in the same years.

${ }^{2}$ In the European Union, for example, only four member states out of 27 (Austria, Denmark, France and Italy) apply tax schemes that permit a cross-border loss offset. See European Commission (2006).

${ }^{3}$ Nevertheless the ECJ permitted the U.K. government to deny the parent company of Marks and
} 
Since the ECJ's initial ruling in the Marks and Spencer case, the issue of what constitutes a 'final loss' that qualifies for cross-border loss relief has been the subject of several further decisions by national courts and the ECJ (see Boulogne and Slavnic, 2012). While the issue is still not fully solved, it is very likely that EU member states will be legally obliged to offer some form of cross-border tax relief to multinational businesses. In the wake of the Marks and Spencer ruling, the European Commission has presented alternative measures for providing a coordinated cross-border loss relief, which differ primarily in whether the loss transfer from the subsidiary to the parent country would be temporary or definitive (see European Commission, 2006). Moreover, a full cross-border loss offset would be a direct implication of introducing a common consolidated corporate tax base (CCCTB) in the European Union, which has recently been proposed by the European Commission (2011).

Despite its immediate policy relevance, the introduction of a coordinated scheme of cross-border loss compensation has so far received only very little attention in formal theoretical analyses. In this paper we contribute to filling this gap. A particular focus of our analysis lies on the question of how the introduction of a coordinated form of cross-border loss offset will affect corporate tax competition in Europe. Corporate tax rates have fallen around the world, but the reduction has been particularly strong in Europe. Between 1995 and 2011, statutory corporate tax rates fell from $35 \%$ to $23 \%$ in the average of the EU-27 countries, and thus substantially more than in the non-EU member states of the OECD (see Eurostat 2011, Tables II-4.1 and II-4.2). Moreover, recent empirical work confirms the existence of strategic interaction in corporate tax setting among OECD countries in general, but in particular among the member states of the European Union (Devereux et al. 2008; Davies and Voget, 2008).

The European Commission has also made it very clear that the introduction of crossborder loss compensation will not be accompanied by corporate tax rate harmonization in the EU. Therefore, it is a central question whether, and how, the incentives for tax competition in Europe would be changed by this reform.

To study the effects of cross-border loss offset on international tax competition, we set up a symmetric two-country framework where two representative multinational enterprises (MNEs) choose both the size of a risky investment project and a transfer

Spencer to deduct the losses incurred by its subsidiaries in Belgium, France and Germany from its positive taxable profits in the United Kingdom, because it did not consider the subsidiaries' losses to be 'final'. See Lang (2006) for a critical discussion of the ECJ's line of argument. 
price that allows each firm to shift profits between its headquarter and the subsidiary, located in different countries. Our analysis is based on current international tax rules, known as 'separate accounting', where the parent and the subsidiary of a multinational firm are taxed as independent entities. On the one hand, our model thus captures the positive effects of coordinated measures of cross-border loss compensation on the investment incentives for multinational firms. On the other hand, we incorporate tax competition by modeling two countries that non-cooperatively set their tax rates in order to attract the profits of MNEs.

In our benchmark scenario, we assume that the parent country of the MNE bases the tax rebate to the loss-making subsidiary on its own, home country tax rate. This corresponds to the current practice in those countries that offer a unilateral cross-border loss offset to resident MNEs (see footnote 2). Moreover, this scheme also underlies the European Commission's proposals for a coordinated cross-border tax relief. We show that when this scheme is applied, an increase in loss offset opportunities is likely to lead to falling tax rates in equilibrium, and hence to intensified tax competition, at least when loss offset is almost complete in equilibrium. The fall in equilibrium tax rates will in turn cause tax revenue losses for each country to be even larger than is implied by the direct effect of the reform. The reason underlying this result is simple: maintaining a high corporate tax rate becomes more costly under cross-border loss compensation, because it induces a higher tax rebate to loss-making subsidiaries of resident MNEs.

We then show that the negative side effects of cross-border loss compensation can be avoided under an alternative loss offset scheme where tax rebates are based on the tax rate in the subsidiary's host country. In contrast to the benchmark loss offset scheme, equilibrium tax rates will rise in this scenario following the reform. This is because an increase in each country's own tax rate is not accompanied by higher tax rebates to loss-making subsidiaries, but more generous loss offset provisions increase investment and thus the corporate tax base. As a result, tax revenue losses will be smaller under this alternative scheme than is implied by the direct effect of enhanced cross-border loss compensation.

We analyze the robustness of our results by considering alternative government objective functions, an endogenous risk choice by the MNEs, and asymmetries between the competing countries. These analyses show that the advantages of the alternative loss offset scheme are maintained in most of the extended settings. We conclude, therefore, that if cross-border loss compensation is introduced in the European Union - either 
because of its economic advantages, or to satisfy legal non-discrimination rules - the cross-border tax relief should be based on the tax rate of the country in which the losses occur (the host country). If instead, current plans are realized and the tax rebate is based on the tax rate of the country granting the tax relief (the home country), then it must be expected that the introduction of cross-border tax relief will further fuel the ongoing tax competition in Europe.

In the related literature, most theoretical and empirical studies have analyzed the effects of incomplete loss compensation in a closed economy setting. Theoretical analyses have focused mostly on the effects on investment and risk-taking decisions over time (e.g. Eeckhoudt et al., 1997; Pantheghini, 2001). The empirical literature has estimated the response of investment decisions to tax law asymmetries in the United States (Altshuler and Auerbach, 1990) and in the United Kingdom (Devereux et al., 1994). In general, these studies have found significant negative investment effects of imperfect loss compensation. More recently, these effects have been reassessed using more detailed empirical models and richer data sources (Edgerton, 2010; Dwenger and Walch, 2011). In recent years, a few papers have analyzed loss offset in an international setting, but this literature is still very small. Among the empirical studies, Niemann and Treisch (2005) perform a Monte Carlo simulation analysis of the unilateral introduction of cross-border loss compensation in Austria (see footnote 2). Fuest et al. (2007) estimate the tax revenue effects of a switch to a complete cross-border loss offset under the CCCTB and find that, in the EU average, the corporate tax base falls by $20 \%$ as a result of this change. Dressler and Overesch (2013) analyze the impact of national loss offset regimes on MNEs' investment decisions and find mixed empirical support for the claim that generous loss offset provisions increase foreign direct investment.

Little is known, however, about how the introduction of cross-border loss offset shapes national corporate tax policies in a setting of international tax competition. Gérard and Weiner $(2003,2006)$ study this issue in a framework where MNEs are taxed under formulary apportionment, but they do not derive the full equilibrium changes in tax rates that follow from the reform. Closest to our paper is Kalamov and Runkel (2012), who derive the non-cooperative equilibrium when countries compete over both tax rates and the rate of cross-border loss offset. Their analysis is based on a setting where each country grants cross-border tax relief based on its own tax rate. The authors find that decentralized loss offset provisions are set efficiently when countries compete for real investment, whereas individual countries choose inefficiently high levels of cross-border 
loss offset when they compete for profit shifting. The analysis of Kalamov and Runkel is thus complementary to ours, as we focus on the coordinated introduction of crossborder loss relief and study how this affects tax rate competition under two alternative loss offset regimes.

This paper is structured as follows. Section 2 introduces the basic framework for our analysis. Section 3 analyzes the effects of cross-border loss offset under the benchmark scheme, where the tax rebate is based on the tax rate in the parent's home country. Section 4 carries out the same analysis under the alternative loss offset scheme, where the tax rate of the subsidiary's host country is used for the tax rebate. Section 5 analyzes several extensions of our basic model. Section 6 concludes.

\section{The basic framework}

We consider a simple one-period model of two small countries, labeled 1 and 2. There are two representative MNEs, each with a parent company in one country and with a subsidiary in the other country. We label firm $i \in\{1,2\}$ by the country in which the parent is located. Capital is assumed to be perfectly mobile internationally and is supplied to the firms by the international capital market at an exogenous interest rate normalized to one. Finally, we assume in our benchmark model that both firms and countries are perfectly symmetric. This excludes redistributive tax revenue effects that arise from tax rate differentials in a setting with cross-border loss compensation. Hence our benchmark model focuses squarely on the efficiency of firms' investment choices and governments' tax policies. Asymmetries between countries will be introduced in the extensions (Section 5.3).

The two MNEs produce a homogeneous good for the world market, at a world price normalized to one. Production occurs with capital and a fixed factor, following the production function $f\left(k_{i}\right)$, with $f_{k}>0$ and $f_{k k}<0$. Hence pure profits arise from decreasing returns to scale in production.

Each MNE makes two sets of choices. First, each firm chooses the level of investment $k_{i}$. We assume, for simplicity, that this investment choice is made only by the subsidiary of firm $i$ (which is located in country $j$ ). In our benchmark model, the investment is successful with an exogenous probability $p$, and unsuccessful with probability $1-p .{ }^{4}$

\footnotetext{
${ }^{4}$ In Section 5.2 we allow firms to endogenously choose the success probability of the investment.
} 
These probabilities are identical for both MNEs. The parent company of each firm has an exogenous profit income equal to $\bar{G}_{i}$, which is sufficient to cover all possible losses of the subsidiary. ${ }^{5}$

Second, each MNE is able to shift profits between the headquarter and the subsidiary, in order to save taxes. The simplest way to model this is through manipulated transfer prices. ${ }^{6}$ Hence we assume that the headquarter provides an overhead service to the subsidiary, whose true value is normalized to zero for analytical convenience. Declaring a manipulated transfer price $q_{i}>0$ will therefore shift profits from the subsidiary to the headquarter country, whereas a transfer price $q_{i}<0$ does the reverse. Profit shifting imposes costs for legal counseling or expected fines that are assumed to be quadratic in the deviation from the true value of the overhead service and are given by $C\left(q_{i}\right)=b q_{i}^{2} / 2$. The MNEs behave in a risk-neutral way and maximize their net expected payoff.

Corporate income taxes are modeled as proportional taxes on profits. We assume that taxes are imposed by the source country of the investment. ${ }^{7}$ This implies that country $j$ taxes the profits of the subsidiary of firm $i$, whereas the parent country of this firm, $i$, exempts this income from tax. Moreover, our analysis focuses on the effects that crossborder loss offset introduces under the current principle of separate accounting, where the parent and the subsidiary of a multinational firm are taxed as separate entities. ${ }^{8}$

\footnotetext{
${ }^{5}$ Alternatively, we could assume that the parent company of each MNE takes the same decisions as the subsidiary. This, however, would reduplicate the decisions taken within each MNE, increasing the complexity of the analysis without adding additional insights.

${ }^{6}$ An alternative channel for profit shifting that has attracted much recent interest is debt shifting within the multinational firm (see Schindler and Schjelderup, 2012 for a theoretical analysis and Egger et al., 2010, for empirical evidence). Modeling debt shifting is slightly more complex than the modeling of strategic transfer price setting, however, and the implications for tax competition between countries, on which the present analysis is focused, are identical.

${ }^{7}$ The source principle of taxation, where the profits of a subsidiary are tax-exempt in the country of the parent firm, is followed by the overwhelming majority of OECD countries. One of the few exceptions is the United States which is, however, also contemplating a switch to the exemption method. See Becker and Fuest (2010) for a recent discussion and analysis.

${ }^{8}$ In contrast, Gérard and Weiner $(2003,2006)$ base their analysis of cross-border loss offset on a system of formulary apportionment, where the total profits of a MNE are aggregated and then allocated to the various host countries according to a predetermined formula. It is well-known that the tax incentives for national governments can be very different under separate accounting and under formulary apportionment (see e.g. Riedel and Runkel, 2007).
} 
The essential element of our model is cross-border loss offset within the MNE. In our static model, losses incurred in one country cannot be offset against positive future profits in the same country. Hence the one-period model highlights the role of crossborder loss offset by effectively turning all losses incurred in one country into 'final losses' (see the introduction). Specifically, we postulate that if the investment project of firm $i$ 's subsidiary is unsuccessful, then a fraction $0 \leq \alpha \leq 1$ of the losses can be deducted from the exogenous taxable profit income of the parent firm in country $i$. Our analysis thus focuses on a setting where the losses of a subsidiary can be deducted from positive profits made by the parent company. In practice this is the setting in which cross-border loss offset is most likely to be introduced, because it minimizes the possibility that the MNE can abuse loss offset provisions. ${ }^{9}$

\section{Benchmark: Loss offset at the home country's tax}

In this section, we analyze the implications of cross-border loss-offset in the benchmark case where the MNE's home country bases the tax rebate granted for the losses of foreign subsidiaries on its own tax rate. This scheme is currently applied by the countries that offer a unilateral cross-border loss offset and it also underlies the European Commission's proposals for the coordinated introduction of cross-border tax relief.

\subsection{Firms}

Given the corporate tax rates $t_{i}$ and $t_{j}$, the expected after-tax profits of the multinational firm based in country $i$ are

$$
E\left(\pi_{i}\right)=\left(1-t_{i}\right)\left[\bar{G}_{i}+q_{i}\right]+\left(1-t_{j}\right)\left\{p\left[f\left(k_{i}\right)-k_{i}\right]-q_{i}\right\}-\left(1-\alpha t_{i}\right)(1-p) k_{i}-\frac{b}{2} q_{i}^{2},
$$

for $i \neq j$. In (1) the first term describes the exogenous profits of the parent company, plus any 'paper profits' shifted to this country, net of the tax rate applied in the parent firm's home country $i$. The second term captures the net profits of firm $i$ 's subsidiary

\footnotetext{
${ }^{9}$ If a parent company's losses can be deducted from the profits of a subsidiary, then the MNE will often have a choice in which country to offset the losses. If the tax rebate is based on the tax rate in the country granting the tax relief, the MNE has an incentive to offset the parent's losses in the host country with the highest tax rate. For this reason, there is considerable skepticism against a 'downward' cross-border tax relief, in contrast to the 'upward' tax relief that we consider here. See European Commission (2006).
} 
in country $j$ in the case where the investment is successful, again corrected for profit shifting. Investment is assumed to fully depreciate in the process of production so that investment costs must be deducted from the value of output. The third term captures the losses incurred by the subsidiary when the investment is unsuccessful, which occurs with probability $(1-p)$. In this case the value of output is zero and the before-tax loss is simply $k_{i}$. This loss is reduced by the tax relief granted in the parent's home country $i$, where the tax credit depends on country $i$ 's tax rate and on the internationally coordinated loss offset factor $\alpha$. Finally, the last term gives the cost of profit shifting, which are assumed to be not deductible from tax.

Maximizing (1) with respect to $k_{i}$ implicitly defines the subsidiary's optimal investment level by

$$
f_{k_{i}}-1-\frac{(1-p)}{p\left(1-t_{j}\right)}\left(1-\alpha t_{i}\right)=0 \quad \forall i \neq j .
$$

In the absence of uncertainty $(p=1)$, the third term on the left-hand side of $(2)$ is zero and the optimal investment level is implicitly determined by the usual condition that the marginal product of capital, $f_{k}$, equals the exogenous world interest rate of unity. In the presence of uncertainty, but in the absence of taxes, the marginal productivity of capital in case of success must rise by $(1-p) / p$, in order to compensate the risk-neutral investor for the possibility of failure. This decision is distorted by a tax system that taxes positive profits but grants no tax relief for losses incurred. If no cross-border loss offset occurs at all $(\alpha=0)$, the marginal product of capital must rise by $(1-p) /\left[p\left(1-t_{j}\right)\right]$. This implies an underinvestment by the subsidiary that is the more severe, the higher is country $j$ 's tax rate. Introducing cross-border loss offset counteracts this distortion, but it will only fully eliminate it when the loss offset parameter $\alpha$ equals one and tax rates in both countries are identical.

The MNEs optimality condition with respect to the transfer price $q_{i}$ is given by

$$
q_{i}=\frac{t_{j}-t_{i}}{b} \quad \forall i \neq j
$$

Setting $q_{i}>0$, that is shifting profits from the subsidiary in country $j$ to the parent in country $i$, will thus be profitable to the extent that $t_{j}>t_{i}$.

From (2) and (3) the effects of taxes on the firm's optimal choices of $k_{i}$ and $q_{i}$ are:

$$
\begin{array}{rlrl}
\frac{\partial k_{i}}{\partial t_{i}}=-\frac{\alpha(1-p)}{p\left(1-t_{j}\right) f_{k_{i} k_{i}}} \geq 0, & \frac{\partial k_{i}}{\partial t_{j}}= & \frac{\left(1-\alpha t_{i}\right)(1-p)}{p\left(1-t_{j}\right)^{2} f_{k_{i} k_{i}}}<0, \\
\frac{\partial q_{i}}{\partial t_{i}}=\frac{-1}{b}<0, & \frac{\partial q_{i}}{\partial t_{j}}=\frac{1}{b}>0 .
\end{array}
$$


Equation (4) shows that an increase in country $j$ 's tax rate leads to less capital investment by the subsidiary of firm $i{ }^{10}$ In contrast, by increasing the expected tax rebate, an increase in the tax rate of country $i$ increases capital investment by firm $i$ 's subsidiary when the loss offset parameter $\alpha$ is strictly positive. Equation (5) states that a tax increase in either country leads to profits being shifted to the other country.

\subsection{Governments}

In our benchmark model, we postulate that governments maximize their corporate tax revenues. This objective captures the concern about tax revenues that features prominently in both policy debates and court decisions on cross-border loss offset. From a theoretical perspective, the assumption that the profit income of MNEs does not enter the governments' objective function corresponds to a setting where the residents of each country invest their capital in perfectly diversified global portfolios. ${ }^{11}$ The implications of an extended government objective that also incorporates the profits of home-based multinationals are considered in Section 5.1.

Country $i$ 's tax base consists of the exogenous profit income $\bar{G}_{i}$, less the share $\alpha$ of the losses made by the subsidiary of firm $i$ if its investment fails. To these are added the profits made by the subsidiary of firm $j$ when this firm's investment is successful. Finally, tax revenues are affected by the net effect of profit shifting in both MNEs. Tax revenues in each country are then given by

$$
T_{i}=t_{i}\left\{\bar{G}_{i}-\alpha(1-p) k_{i}+p\left[f\left(k_{j}\right)-k_{j}\right]+q_{i}-q_{j}\right\} \equiv t_{i} B_{i} \quad \forall i \neq j .
$$

The possibility to attract profits from both MNEs thus gives rise to tax competition between the two countries. As in all models of symmetric tax competition, the possibility of profit shifting by MNEs suffices to constrain non-cooperating countries in the setting of their optimal tax rates, even if no profit shifting actually occurs in equilibrium.

Maximizing with respect to $t_{i}$ gives country $i$ 's optimal tax rate in implicit form:

$$
t_{i}^{*}=\frac{B_{i}}{-\Omega_{i}}>0 \quad \forall i,
$$

\footnotetext{
${ }^{10}$ Recall that the subscript $i$ refers to the headquarter country of multinational $i$, but the subsidiary's investment occurs in country $j$. Therefore the well-known negative effect of source-based taxes on investment is given by $\partial k_{i} / \partial t_{j}$ in our notation.

${ }^{11}$ Empirically, globally diversified portfolios are a plausible scenario when most of the small country's capital is invested through financial intermediaries, such as pension funds or insurance companies.
} 
where the profit tax base $B_{i}$ is given in (6) and

$$
\Omega_{i} \equiv\left[p\left(f_{k_{j}}-1\right) \frac{\partial k_{j}}{\partial t_{i}}-\alpha(1-p) \frac{\partial k_{i}}{\partial t_{i}}+\frac{\partial q_{i}}{\partial t_{i}}-\frac{\partial q_{j}}{\partial t_{i}}\right]<0
$$

collects the sum of effects that an increase in $t_{i}$ has on country $i$ 's tax base via the investment decisions (the first two terms in the squared bracket) and the profit-shifting decisions (the last two terms) of both representative MNEs. From (4) and (5), these effects are all negative. The optimal tax policy thus follows a straightforward inverse elasticity rule: it rises with the total value of country $i$ 's tax base $B_{i}$, but falls in the aggregate response of the tax base to a tax increase in country $i$.

\subsection{The effects of cross-border loss offset}

The core question of our analysis is how a coordinated increase in the loss offset parameter $\alpha$ affects optimal tax rates and equilibrium tax revenues. To determine the effects on optimal tax rates, differentiating (7) with respect to $\alpha$ yields

$$
\frac{\mathrm{d} t_{i}^{*}}{\mathrm{~d} \alpha}=\frac{1}{-\Omega_{i}} \frac{\partial B_{i}}{\partial \alpha}+\frac{B_{i}}{\Omega_{i}^{2}} \frac{\partial \Omega_{i}}{\partial \alpha} .
$$

The first term in (9) gives the change in country $i$ 's tax base following an increase in the loss offset parameter $\alpha$. To sign this effect we derive the impact effects of a change in $\alpha$ on $k_{i}{ }^{12}$ Implicitly differentiating (2) shows that increased cross-border loss compensation raises investment by both subsidiaries:

$$
\frac{\partial k_{i}}{\partial \alpha}=-\frac{t_{i}(1-p)}{\left(1-t_{j}\right) p f_{k_{i} k_{i}}}>0 \quad \forall i \neq j .
$$

When countries are symmetric, the change in country $i$ 's tax base following an increase in $\alpha$ is given by

$$
\frac{\partial B_{i}}{\partial \alpha}=-(1-p) k-(1-\alpha) \frac{t(1-p)^{2}}{(1-t)^{2} p f_{k k}} .
$$

The first term in (11) gives the negative, direct effect on country $i$ 's tax base that results from the increased tax rebate to the loss-making subsidiary of its MNE. The second term captures the indirect effects through the induced change in the MNEs' investment behavior. The expansion of risky activities in firm $i$ 's subsidiary reduces country $i$ 's expected tax base, because the government of country $i$ participates only

\footnotetext{
${ }^{12}$ By impact effect we mean the direct effect of the exogenous parameter change, without taking into account the induced changes in governments' tax policies.
} 
in the losses, but not in the profits of this subsidiary. Matters are exactly reversed for the subsidiary of firm $j$, where country $i$ taxes the increased profits in case of success, but does not share in the losses if the investment fails.

In general, it is therefore not possible to sign the change in country $i$ 's tax base that results from an increase in $\alpha$. The net effect can be signed, however, when cross-border loss compensation is almost complete and $\alpha \rightarrow 1$. In this case, the indirect effects in (11) sum to zero. Intuitively, with full loss offset, the firm's optimal investment condition implies that the expected increase in the tax base from a successful investment of subsidiary $j$ is exactly offset by the expected loss of an unsuccessful investment of subsidiary $i$. Hence only the negative direct effect remains, giving

$$
\left.\frac{\partial B_{i}}{\partial \alpha}\right|_{\alpha \rightarrow 1}=-(1-p) k<0 .
$$

In the following we will also refer to this direct effect as the mechanical effect of the reform.

Next, we analyze the effect of improved loss offset opportunities on the elasticity of country $i$ 's tax base, as given by $\Omega_{i}$. To differentiate (8) with respect to $\alpha$, we use the first-order condition for capital investment (2) and the impact effect of cross-border loss offset on capital investment (10). Further differentiating the tax sensitivities of capital investments in (4) with respect to $\alpha$ gives

$$
\frac{\partial \Omega_{i}}{\partial \alpha}=\frac{2(1-p)^{2}}{(1-t)^{3} p f_{k k}}[\alpha-t-2 \alpha t(1-t)] .
$$

The sign of (13) is ambiguous, in general. However, when loss offset is almost complete $(\alpha \rightarrow 1)$ and the tax rate is not too high $(t<0.5)$, it is straightforward to show that the sign of (13) is negative, implying that a rise in $t_{i}$ leads to a larger tax base loss when cross-border loss offset is improved. Using this result along with (12) in (9) gives the result that improved loss offset conditions will reduce equilibrium tax rates in both countries. This is summarized in:

Proposition 1a Consider a symmetric Nash equilibrium in tax rates where governments maximize tax revenues and the losses of subsidiaries are rebated at the tax rate of the parent's home country. Then a small increase in cross-border loss offset d $\alpha>0$ reduces equilibrium tax rates in both countries, if loss offset is almost complete $(\alpha \rightarrow 1)$ and tax rates are not too high initially $(t \leq 1 / 2)$. 
Proposition 1a points to an important and, as yet, little studied side effect of coordinated arrangements to increase cross-border tax relief. Given that governments remain free to set profit tax rates non-cooperatively, improving the international tax deductibility of losses is likely to make international tax competition more aggressive. The reason is that cross-border loss offset increases the costs of maintaining a high tax rate, when each country grants an international loss offset based on its own tax rate. This effect is the stronger the higher is the degree of loss offset $\alpha$.

We now derive the equilibrium change in tax revenues following an increase in $\alpha$. Writing $T_{i}=T_{i}\left[\alpha, t_{i}(\alpha), t_{j}(\alpha)\right]$ and differentiating with respect to $\alpha$ gives $^{13}$

$$
\frac{\mathrm{d} T_{i}}{\mathrm{~d} \alpha}=\frac{\partial T_{i}}{\partial \alpha}+\frac{\partial T_{i}}{\partial t_{j}} \frac{\mathrm{d} t_{j}}{\mathrm{~d} \alpha} .
$$

The first term in (14) captures the direct effect of $\alpha$ on the tax base, and hence tax revenues, for constant tax rates $t_{i}$. From (11) and (2) this effect can be expressed as

$$
\frac{\partial T_{i}}{\partial \alpha}=t\left[-(1-p) k+\frac{(1-p)(1-\alpha)}{(1-t)} \frac{\partial k}{\partial \alpha}\right] .
$$

The first effect in the squared bracket is again the direct or mechanical effect of the reform, which is now valued with country $i$ 's tax rate. The second term gives the net change in country $i$ 's tax revenues through the behavioral responses of both subsidiaries. In case of success, tax revenues increase with an investment expansion of firm $j$, but decrease with a higher investment of firm $i$. The net effect will be positive as long as cross-border loss offset is incomplete. We have already shown, however, that the second effect goes to zero, and the tax base change is unambiguously negative, when $\alpha \rightarrow 1$ [see eq. (12)].

To obtain the general equilibrium change in tax revenues, it remains to sign the externality that the induced tax change in the other country $j$ has on country $i$ 's tax base. From (6) we can show that country $i$ 's tax base will unambiguously rise following a tax increase in country $j$ :

$$
\frac{\partial T_{i}}{\partial t_{j}}=2 t\left[\frac{1}{b}-\frac{\alpha(1-p)^{2}(1-\alpha t)}{p(1-t)^{2} f_{k k}}\right]>0 .
$$

The first effect in (16) shows that country $i$ 's tax base rises from profit shifting into the country as a result of the higher tax rate abroad. Secondly, a rise in $t_{j}$ increases

\footnotetext{
${ }^{13}$ Note that the effect of country $i$ 's own tax rate on its tax revenues $T_{i}$ is zero from the envelope theorem.
} 
the value of the loss offset that firm $j$ can obtain for any given and positive level of $\alpha$. This increases investment by firm $j$ 's subsidiary and thus the tax base of country $i$. Lastly, a higher tax rate in country $j$ reduces firm $i$ 's investment there, thus reducing the volume of tax rebates that country $i$ has to grant its resident MNE.

Hence, the total effect of the externality depends on how equilibrium tax rates change with increased cross-border loss offset. From Proposition 1a we know that tax rates in both countries will fall in a symmetric Nash equilibrium when cross-border loss offset is almost complete and initial tax rates are not too large. In this case the second effect in (14) is thus negative and adds to the negative first effect. Hence equilibrium tax revenues in both countries will fall. Moreover, due to the downward adjustment of tax rates, tax revenue losses in both countries will exceed the revenue losses from the mechanical effect. We summarize our findings in:

Proposition $1 \mathbf{b}$ When the losses of subsidiaries are rebated at the tax rate of the parent's home country, then a small increase in cross-border loss offset $d \alpha>0$ lowers equilibrium tax revenues in each country by more than the mechanical effect, if loss offset is almost complete $(\alpha \rightarrow 1)$ and tax rates are not too high initially $(t \leq 1 / 2)$.

Proposition $1 b$ implies that a marginal increase in the degree of cross-country tax relief to the point of full loss offset is definitely undesirable for revenue-maximizing governments, as it reduces both the equilibrium tax base and the optimal rate of corporation tax. Fuest et al. (2007) have isolated the direct tax base effect (mechanical effect) of switching to a complete cross-border loss offset and have estimated that this reduces corporate tax revenues in the EU average by roughly $20 \%$. Our analysis shows that equilibrium tax revenue losses can be expected to be even higher, if the behavioral responses of firms and governments are taken into account.

\section{An alternative loss offset scheme}

Our analysis in the previous section has shown that introducing cross-border loss offset is likely to intensify tax competition when the MNE's home country bases the tax rebate for the losses of foreign subsidiaries on its own tax rate. This suggests an alternative loss offset scheme, where the home country still grants a tax rebate for the losses of its foreign-based subsidiaries, but applies the tax rate of the subsidiary's host country 
to the loss offset. ${ }^{14}$ One immediate advantage of this alternative scheme is that the same tax rate is applied to both positive and negative returns on investment. In the following we analyze this scheme in more detail, focussing again on the issue of how international tax competition is affected by cross-border loss compensation.

\subsection{Firms and governments}

With the changed specification of loss compensation, the expected after-tax profits of firm $i$ are given by

$$
E\left(\pi_{i}\right)=\left(1-t_{i}\right)\left[\bar{G}_{i}+q_{i}\right]+\left(1-t_{j}\right)\left\{p\left[f\left(k_{i}\right)-k_{i}\right]-q_{i}\right\}-\left(1-\alpha t_{j}\right)(1-p) k_{i}-\frac{b}{2} q_{i}^{2} .
$$

The only difference between (17) and equation (1) in the last section lies in the third term, where losses are now rebated at the tax rate $t_{j}$ of the subsidiary's host country. Optimal profit shifting behavior does not change under the alternative loss offset scheme, so that equations (3) and (5) from Section 3 continue to apply. Optimal investment decisions are affected, however, and are now implicitly determined by

$$
f_{k_{i}}-1-\frac{(1-p)}{p\left(1-t_{j}\right)}\left(1-\alpha t_{j}\right)=0 \quad \forall i \neq j .
$$

Differentiating (18) with respect to the tax rates $t_{i}$ and $t_{j}$ yields

$$
\frac{\partial \tilde{k}_{i}}{\partial t_{i}}=0, \quad \frac{\partial \tilde{k}_{i}}{\partial t_{j}}=\frac{(1-\alpha)(1-p)}{p\left(1-t_{j}\right)^{2} f_{k_{i} k_{i}}} \leq 0 \quad \forall i \neq j,
$$

where the tilde indicates that we are now evaluating all effects at the alternative loss offset scheme. Under this scheme, the tax rate in the parent country $i$ has no effects on firm $i$ 's choices. This is, of course, a result of our simplifying assumption that the investment level of the parent company is fixed. At the same time, the tax rate of the host country $j$ now applies to both positive and negative profits. Eq. (19) shows that the net effect of $t_{j}$ on the investment level of firm $i$ 's subsidiary is negative when loss compensation is incomplete. If $\alpha=1$, the distortion arising from source-based capital taxation disappears and the tax $t_{j}$ becomes a lump-sum tax.

As before, the objective of both governments is to maximize tax revenues. When country $i$ applies the foreign tax rate $t_{j}$ to calculate the tax rebate granted to the subsidiary of its home-based MNE, its tax revenues are

$$
\tilde{T}_{i}=t_{i}\left\{\bar{G}_{i}+p\left[f\left(\tilde{k}_{j}\right)-\tilde{k}_{j}\right]+\tilde{q}_{i}-\tilde{q}_{j}\right\}-\alpha t_{j}(1-p) \tilde{k}_{i} \equiv t_{i} \tilde{B}_{i}-\alpha t_{j}(1-p) \tilde{k}_{i} .
$$

\footnotetext{
${ }^{14}$ We thank Clemens Fuest for the suggestion to study this alternative loss offset scheme.
} 
Maximizing with respect to $t_{i}$ gives

$$
\tilde{t}_{i}^{*}=\frac{\tilde{B}_{i}}{-\tilde{\Omega}_{i}}>0, \quad \tilde{\Omega}_{i}=p\left(f_{k_{j}}-1\right) \frac{\partial \tilde{k}_{j}}{\partial t_{i}}+\frac{\partial \tilde{q}_{i}}{\partial t_{i}}-\frac{\partial \tilde{q}_{j}}{\partial t_{i}}<0 .
$$

Note, from the definition of $\tilde{B}_{i}$ in (20), that the tax rebate to the loss-making subsidiary does not enter the numerator of the optimal tax rate $\tilde{t}_{i}^{*}$ under this loss offset scheme.

\subsection{The effects of cross-border loss offset}

To analyze the effects of cross-border loss offset, we proceed as in the last section to determine the effects on optimal tax rates [see eq. (9)]. The impact effect of a change in $\alpha$ on investment is again unambiguously positive under the alternative loss offset scheme. An important difference to the analysis in the previous section is, however, that the loss offset parameter $\alpha$ now affects $\tilde{B}_{i}$ only through the investment level of firm $j$ :

$$
\frac{\partial \tilde{k}_{j}}{\partial \alpha}=-\frac{t_{i}(1-p)}{\left(1-t_{i}\right) p f_{k_{j} k_{j}}}>0, \quad \frac{\partial \tilde{B}_{i}}{\partial \alpha}=p\left(f_{k_{j}}-1\right) \frac{\partial \tilde{k}_{i}}{\partial \alpha}>0 \quad \forall i \neq j .
$$

In stark contrast to our previous specification [see eq. (12)], we get the global result that the numerator of each country's optimal tax expression is unambiguously rising in $\alpha$ under the alternative loss offset scheme. Turning to the denominator of $\tilde{t}_{i}^{*}$ in $(21)$, differentiating with respect to $\alpha$ and using (18) and (19) yields:

$$
\frac{\partial \tilde{\Omega}_{i}}{\partial \alpha}=-\frac{(1-p)^{2}\left[\left(1-\alpha t_{i}\right)+t_{i}(1-\alpha)\right]}{p\left(1-t_{i}\right)^{3} f_{k_{j} k_{j}}}>0 .
$$

This shows that the elasticity with which country $i$ 's tax base responds to tax changes in $t_{i}$ is unambiguously falling in $\alpha$. We thus get

Proposition 2a Consider a symmetric Nash equilibrium in tax rates where governments maximize tax revenues and losses of subsidiaries are rebated at the tax rate of the subsidiary's host country. Then a small increase in cross-border loss offset d $\alpha>0$ increases equilibrium tax rates in both countries for any level of $\alpha$.

In direct contrast to Proposition 1a in the previous section, Proposition 2a states that country $i$ 's optimal tax rate is unambiguously and globally rising in $\alpha$ when countries grant cross-border tax relief at the rate of the subsidiary's host country. Hence tax competition is mitigated under the alternative tax relief scheme. The core reason for 
this result is that an increase in the loss offset parameter has no negative direct effect on optimal tax rates in both countries. At the same time, the induced investment expansion of both MNEs increases tax bases in both countries and thus offers an incentive to increase tax rates.

To compute the equilibrium changes in tax revenues, we follow (14) and first consider the direct effect, ignoring for now the tax rate changes induced by enhanced crossborder loss offset. The direct effect on tax revenues is:

$$
\frac{\partial \tilde{T}_{i}}{\partial \alpha}=\tilde{t}\left[-(1-p) \tilde{k}+\frac{(1-p)(1-\alpha)}{(1-\tilde{t})} \frac{\partial \tilde{k}}{\partial \alpha}\right] .
$$

The structure of (24) is analogous to the corresponding direct effect in the previous section [see eq. (15)]. The negative first term gives the mechanical effect of the reform, whereas the second term collects the effects on tax revenue via behavioral adjustments. The second term is positive whenever loss offset is incomplete so that the returns to higher capital investments are taxed, on net, by the two governments. When $\alpha \rightarrow 1$, however, the second effect goes to zero and only the negative statutory effect remains.

We now turn to the effects of tax competition. The tax externality $\partial \tilde{T}_{i} / \partial t_{j}$ can be calculated from government $i$ 's tax revenues by differentiating $(20)$ with respect to $t_{j}$, using (5) and (19). This gives:

$$
\frac{\partial \tilde{T}_{i}}{\partial t_{j}}=\frac{2 \tilde{t}}{b}-\tilde{t} \frac{\alpha(1-\alpha)(1-p)^{2}}{p(1-\tilde{t})^{2} f_{k k}}-\alpha(1-p) \tilde{k} .
$$

Equation (25) shows three distinct effects that a tax increase in country $j$ has on tax revenues in country $i$. The first two effects are analogous to our analysis in the previous section [see eq. (16)] and are both positive. By the first effect, a tax increase in country $j$ will lead to profit shifting into country $i$, irrespective of how tax rebates are calculated. The second effect is strictly positive for $0<\alpha<1$, as an increase in $t_{j}$ reduces the investment of firm $i$ 's subsidiary, and therefore reduces the expected tax rebate of country $i$. There is a counteracting third effect in (25), however, which is specific to tax rebates being based on the tax rate in the subsidiary's host country: by raising its tax rate, the host country $j$ can raise the rate at which country $i$ has to grant tax relief to the subsidiary of its home-based MNE. Taken in isolation, this effect thus provides an incentive for strategic overtaxation under the alternative loss offset scheme, as an increase in $t_{j}$ raises the tax applied to a successful project, which is collected by country $j$, whereas the simultaneous increase in the tax rebate in the event of a loss is paid for by the other country $i$. 
Since we know from Proposition 2a that tax rates are rising in $\alpha$ under the alternative loss offset regime, the indirect effect on country $i$ 's tax revenues is positive, iff the net externality in (25) is positive. This will be true, in particular, if $\alpha$ is sufficiently low initially so that the negative third effect is small. In this case, the increase in tax rates induced by enhanced cross-border loss offset under the alternative scheme will lead to a positive indirect effect on each country's tax revenues. Together with the non-negative second effect in (24) this ensures that revenue losses are smaller for each country than is implied by the mechanical effect of the reform. This is summarized in:

Proposition $\mathbf{2} \mathbf{b}$ When the losses of subsidiaries are rebated at the tax rate of the subsidiary's host country, then a small increase in cross-border loss offset $d \alpha>0$ lowers equilibrium tax revenues in each country by less than the mechanical effect, if the loss offset parameter $\alpha$ is sufficiently low initially.

Comparing Proposition $2 \mathrm{~b}$ to Proposition $1 \mathrm{~b}$ in the previous section shows that the revenue effects of cross-border loss offset are very different under the two loss offset schemes. The tax revenue losses that arise from the mechanical effect of more generous loss offset provisions will likely be enlarged by behaviorial effects when parent countries of MNEs base tax rebates for loss-making subsidiaries on their own tax rate, whereas revenue losses will be reduced in size when each parent country uses the foreign tax rate to calculate its tax rebate. These opposite behavioral effects arise from the contrasting incentives to adjust optimal tax rates that exist under the two loss offset regimes.

Since many of our theoretical results hold strictly only for certain ranges of the loss offset parameter $\alpha$, we conclude this section by offering some representative simulation results that compare the two loss offset schemes. For this purpose we specify the production function of both representative firms as $f\left(k_{i}\right)=\phi k_{i}^{0.5}$. We present simulation results for both a low and a high value of the productivity parameter $\phi(\phi=4$ and $\phi=6$, respectively). Moreover, we consider two different intensities of tax competition for the allocation of profits: a regime of low shifting costs $(b=0.2)$ and aggressive tax competition, and a regime of higher shifting costs $(b=0.5)$ and moderate tax competition. In each scenario we consider alternative values for the loss offset parameter $\alpha$. The results are summarized in Table 1.

For the benchmark scheme, Table 1 shows that tax rates need not monotonically fall, and may indeed rise in equilibrium as long as the degree of loss offset is low initially. This is seen in the scenario with high productivity $(\phi=6)$ and moderate tax competition 
Table 1: Tax rate and tax revenue effects of alternative loss offset schemes

\begin{tabular}{|c|c||cc|cc||cc|cc|}
\hline & \multicolumn{1}{|c||}{} & \multicolumn{3}{c||}{ benchmark scheme } & \multicolumn{3}{c|}{ alternative scheme } \\
\hline & & $\phi=4$ & \multicolumn{2}{c||}{$\phi=6$} & \multicolumn{2}{c|}{$\phi=4$} & \multicolumn{2}{c|}{$\phi=6$} \\
\hline \multirow{3}{*}{$b=0.2$} & $\alpha$ & $t_{i}$ & $T_{i}$ & $t_{i}$ & $T_{i}$ & $t_{i}$ & $T_{i}$ & $t_{i}$ & $T_{i}$ \\
& 0.0 & 0.221 & 0.524 & 0.327 & 1.271 & 0.221 & 0.524 & 0.327 & 1.271 \\
& 0.1 & 0.219 & 0.512 & 0.324 & 1.253 & 0.223 & 0.523 & 0.333 & 1.281 \\
& 0.5 & 0.205 & 0.455 & 0.306 & 1.126 & 0.233 & 0.516 & 0.364 & 1.327 \\
& 1.0 & 0.178 & 0.357 & 0.250 & 0.812 & 0.250 & 0.500 & 0.437 & 1.422 \\
\hline \multirow{5}{*}{$b=0.5$} & 0.0 & 0.433 & 0.947 & 0.514 & 1.779 & 0.433 & 0.947 & 0.514 & 1.779 \\
& 0.1 & 0.433 & 0.946 & 0.515 & 1.791 & 0.441 & 0.961 & 0.525 & 1.814 \\
& 0.5 & 0.422 & 0.910 & 0.507 & 1.781 & 0.484 & 1.030 & 0.589 & 2.002 \\
& 1.0 & 0.360 & 0.719 & 0.414 & 1.347 & 0.625 & 1.250 & 1.000 & 3.250 \\
\hline \hline
\end{tabular}

Notes: $\bar{G}_{1}=\bar{G}_{2}=1 ; p=0.5$

$(b=0.5)$. However, for large initial values of $\alpha$, tax rates are unambiguously falling as the degree of loss offset is further increased (Proposition 1a). Tax revenues follow a similar pattern and may be rising in $\alpha$ when the initial level of cross-border loss offset is low. For high initial values of $\alpha$, however, a further rise in $\alpha$ leads to large tax revenue losses in both countries, which far exceed the mechanical effect (Proposition 1b). ${ }^{15}$

For the alternative scheme, tax rates are seen to be monotonically rising in $\alpha$ in all scenarios (Proposition 2a). Nevertheless, tax revenues may fall as cross-border loss offset increases, as is seen for the scenario with $b=0.2$ and $\phi=4$. However, the reduction in tax revenues will be less than the mechanical effect under this loss offset scheme (Proposition 2b; cf. footnote 15). Hence the fall in tax revenues is far less pronounced in this case, as compared to the benchmark scheme. In the other three scenarios, the induced increase in equilibrium tax rates under the alternative loss offset scheme is even so large that the indirect (behavioral) effects dominate the direct (mechanical) effect and tax revenues are monotonically rising in $\alpha$.

\footnotetext{
${ }^{15}$ We evaluate the magnitude of the mechanical effect for the scenario with $\phi=4$ and $b=0.2$. The investment levels $k_{i}$ are then about one. With $p=0.5$ and $t_{i} \approx 0.2$, the revenue loss from the mechanical effect is then approximately equal to $0.100 d \alpha$ under both loss offset schemes [cf. eq. (15)]. For a switch from no to full cross-border loss offset $(d \alpha=1)$, this corresponds to about $20 \%$ of initial tax revenues, comparable to the results in Fuest et al. (2007). The total revenue loss in this case is $(0.524-0.357) / 0.524 \approx 32 \%$, including the effects of reduced tax rates.
} 


\section{Discussion and extensions}

In this section we extend our analysis in several directions. In Section 5.1 we modify the governments' objective function to account for the profits of home-based multinational firms. In Section 5.2. we allow firms to endogenously choose the success probability of their risky investments. These two extensions are introduced only for the benchmark loss offset scheme, to analyze the robustness of our result that cross-border loss offset intensifies tax competition under this scheme. Finally, in Section 5.3 we introduce asymmetries between countries and compare the two alternative loss offset schemes in a setting where redistributive effects between the two countries are present.

\subsection{Home ownership of multinational firms}

We first analyze how our results for the benchmark loss offset scheme, as analyzed in Section 3, are changed when each government's objective function includes the profits of the resident multinational. ${ }^{16}$ The analytically simplest case arises when the MNE's profits and tax revenues receive the same welfare weight in the government's objective function. There are, however, at least two reasons why governments will value tax revenues more than the profits of home-based MNEs. A first reason is that public goods must be financed by distortionary taxes, implying that one Euro of tax revenues has a higher value for the government than one Euro of private income. Secondly, MNEs are typically not fully owned by the residents of the country in which they are headquartered. ${ }^{17}$

We capture this in our model by incorporating the profits of firm $i$ into country $i$ 's government objective function with a weight of $\lambda \leq 1$. National welfare in country $i$ then equals the weighted sum of the net-of-tax profits of firm $i$ and country $i$ 's tax revenues. From the firm's net profit equation (1) and tax revenues (6), we get

$$
\begin{aligned}
W_{i} & =\lambda E\left(\pi_{i}\right)+T_{i}=\left[\lambda+(1-\lambda) t_{i}\right] \bar{G}_{i}-\left[\lambda+(1-\lambda) \alpha t_{i}\right](1-p) k_{i}+t_{i} p\left[f\left(k_{j}\right)-k_{j}\right] \\
& +\lambda\left(1-t_{j}\right) p\left[f\left(k_{i}\right)-k_{i}\right]+\left[\lambda t_{j}+(1-\lambda) t_{i}\right] q_{i}-t_{i} q_{j}-\frac{\lambda b}{2} q_{i}^{2} \quad \forall i \neq j .
\end{aligned}
$$

\footnotetext{
${ }^{16}$ Recall that the output price of the good produced by the two representative MNEs is fixed in the world market. Consumer surplus is therefore unchanged throughout our analysis.

${ }^{17}$ Huizinga and Nicodème (2006, Table 1), for example, derive a foreign ownership share of more than $20 \%$, on average, for a large sample of 15.000 European firms.
} 
Maximizing with respect to $t_{i}$ and using the firm's first-order condition (2) and symmetry implicitly defines country $i$ 's optimal tax rate. Using the superscript $W$ to indicate variables under a welfare objective, country $i$ 's optimal tax rate is given by

$$
\begin{gathered}
t_{i}^{W}=\frac{B_{i}^{W}}{-\Omega_{i}^{W}}>0, \quad B_{i}^{W}=\left\{(1-\lambda)\left[\bar{G}_{i}-\alpha(1-p) k_{i}\right]+p\left[f\left(k_{j}\right)-k_{j}\right]+q_{i}-q_{j}+\lambda t_{j} \frac{\partial q_{i}}{\partial t_{i}}\right\} \\
\Omega_{i}^{W}=p\left(f_{k_{j}}-1\right) \frac{\partial k_{j}}{\partial t_{i}}-\alpha(1-p) \frac{\partial k_{i}}{\partial t_{i}}+(1-\lambda) \frac{\partial q_{i}}{\partial t_{i}}-\frac{\partial q_{j}}{\partial t_{i}}<0 .
\end{gathered}
$$

In the expression for $t_{i}^{W}$, the numerator $B_{i}^{W}$ is a weighted sum of country $i$ 's tax base and the net profits of firm $i$ and the denominator $\Omega_{i}^{W}$ has been signed using the comparative static results in (4) and (5). To determine the change in tax rates following an increase in the loss offset parameter $\alpha$, the change in the numerator $B_{i}^{W}$ is

$$
\frac{\partial B_{i}^{W}}{\partial \alpha}=-(1-\lambda)\left[(1-p) k_{i}+\alpha(1-p) \frac{\partial k_{i}}{\partial \alpha}\right]+p\left(f_{k}-1\right) \frac{\partial k_{j}}{\partial \alpha} .
$$

A simple benchmark case arises when $\lambda=1$, implying that the profits of the home-based MNE receive the same weight as tax revenues in the government's welfare function. In this case the first term in (27) is zero. Since the second term is unambiguously positive from (10), the numerator in country $i$ 's optimal tax rate is then rising in $\alpha$, in contrast to the analysis in Section 3. The intuition for this reversed sign is that the negative direct effect of a higher loss offset parameter on country $i$ 's tax revenues is matched by an equal increase in the after-tax profits earned by the home-based MNE. With $\lambda=1$ these effects are fully offsetting so that there is no direct effect of the rise in $\alpha$ on country $i$ 's objective function. The indirect effect on investment, and hence on expected profits, is positive, leading to a positive effect of an increase in $\alpha$ on optimal tax rates via the change in $B_{i}^{W}$. Optimal tax rates will thus rise in response to increased cross-border loss offset, if the effect of $\alpha$ on $\Omega_{i}^{W}$ in (26) is also positive. This is the case when $\alpha$ is sufficiently low initially. ${ }^{18}$

As we have argued above, there are several reasons why setting $\lambda<1$ may be a more accurate description of most governments' objective functions. In this more general case, the first term in (27) is negative. In comparison to the benchmark case in Section 3 [see eq. (11)] it will, however, be diminished in size because the negative effect of $\alpha$ on country $i$ 's tax base is partly compensated by the higher net profits of the home-based

\footnotetext{
${ }^{18}$ Comparing (26) with the corresponding value in our benchmark analysis [eq. (8)], the only difference lies in the third term, which is independent of $\alpha$. Hence the conditions for $\partial \Omega_{i}^{W} / \partial \alpha$ to be positive are the same as in the benchmark case [see eq. (13)].
} 
firm. At the same time, the positive second effect is unchanged from our benchmark analysis, because the accompanying profit loss is borne by the residents of the foreign country $j .{ }^{19}$ This is sufficient to show that the optimal tax response to increased crossborder loss compensation will no longer be unambiguously negative when firms' profits enter the government objective, even for $\alpha=1$. In particular, the tax base loss that arises from the mechanical effect of the reform [the first part of the first effect in (27)] matters less for tax policy under the generalized welfare objective, because the benefit of higher rebates accrue to firms that are partly owned by domestic residents.

In practice, it is thus important to evaluate how large the relative profit weight $\lambda$ is in governments' objective functions. Some authors argue that governments generally face political pressures to increase corporate tax revenues, to counter accusations that tax policy contributes to a widening income gap (see e.g. Sørensen, 2007). ${ }^{20}$ Moreover, since most countries do not offer cross-border loss relief at present, governments have already raised substantial concern about the revenue losses that this reform entails. Hence the relative weight $\lambda$ given to the profits of domestically owned firms may be fairly small for the particular policy issue discussed here. If tax revenue considerations are dominant, our benchmark analysis applies and introducing cross-border loss offset at the rate of the MNE's home country is likely to provide incentives for non-cooperating countries to engage in more aggressive tax competition.

\subsection{Endogenous risk choice of firms}

As a second extension of our analysis for the benchmark loss offset scheme, we now let the multinational firms choose the risk-return characteristics of their investments, as given by the success probability $p_{i}$. We postulate that, along the technological frontier, there is an infinite number of investment projects that differ in their success probability, where a riskier investment delivers a higher return in case of success. ${ }^{21}$ The production function is then given by $f\left(p_{i}, k_{i}\right)$ with first-order derivatives $f_{k}>0$ and $f_{p}<0$ and second-order derivatives $f_{k k}<0$ and $f_{p p} \leq 0$. Furthermore risk taking $\left(1-p_{i}\right)$ and

\footnotetext{
${ }^{19}$ This type of tax-exporting effect is familiar from the literature on international capital taxation. See, for example, Huizinga and Nielsen (1997).

${ }^{20}$ Similarly, Rodrik (1998) presents empirical evidence that increased openness of a country, which raises the volatility of incomes, leads to larger government expenditures and therefore to higher tax revenue needs.

${ }^{21}$ See Haufler et al. (2012) for an analysis using this model element in a different policy setting.
} 
Figure 1: The firm's optimal choice of project risk

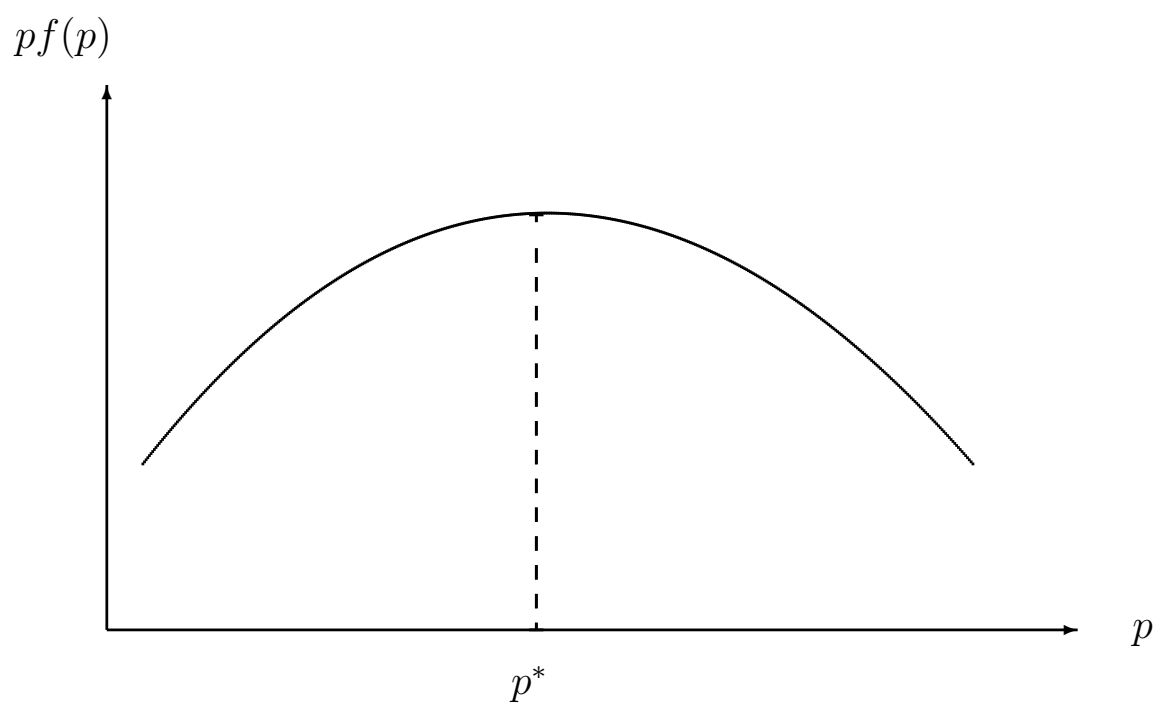

capital investment $k_{i}$ are assumed to be complements, $f_{k p}<0$, implying that the safer is an investment, the lower is the marginal return on capital. Otherwise the model is unchanged from our analysis in Section 3.

In this extended setting, each MNE has three decision variables. The first-order conditions for the investment level and the transfer price are unchanged from (2) and (3). The additional first-order condition for the optimal choice of project risk is

$$
f\left(p_{i}, k_{i}\right)+p_{i} f_{p}\left(p_{i}, k_{i}\right)+\frac{\left(t_{j}-\alpha t_{i}\right)}{1-t_{j}} k_{i}=0 \quad \forall i \neq j .
$$

In the absence of taxes, the third term on the left-hand side is zero and the efficient project choice is determined by the condition $f\left(p_{i}, k_{i}\right)+p_{i} f_{p}\left(p_{i}, k_{i}\right)=0$. For a riskneutral investor this first-order condition maximizes the expected return, $p f(p)$, of the project. This is illustrated in Figure 1, where $p^{*}$ is the efficient level of project risk.

Introducing taxes without a full cross-border loss offset leads to a positive third term on the left-hand side of (28). Hence the negative second term must increase, implying a larger value of $p_{i}$ and hence an inefficiently low level of project risk. In Figure 1 this corresponds to a project choice to the right of the efficient project $p^{*}$. Introducing cross-border loss compensation will reduce this distortion, and it will fully eliminate it when $\alpha=1$ and $t_{i}=t_{j}$.

The full analysis of the extended model is complex, and is relegated to the appendix. It is straightforward, however, to summarize the results of this analysis, because the effects of cross-border loss offset on risk-taking are in many ways parallel to those on 
the investment levels $k_{i}$. A higher degree of loss compensation increases risk-taking (i.e., it reduces $p$ ) and thus the expected return from the investment. This effect increases the (expected) tax base for both countries. At the same time, the expected tax rebates paid to the home-based MNE rise for both countries, due to the higher risk of failure. In a symmetric equilibrium where loss offset is almost complete $(\alpha \rightarrow 1)$, these effects will just offset each other and only the negative mechanical effect of the reform remains [see eq. (12)]. Hence, as in our analysis in Section 3, each country will have an incentive to reduce its tax rate following a rise in $\alpha$, if the level of cross-border loss compensation is already high in the initial equilibrium.

Moreover, each country is again adversely affected by the tax reduction in the other country. In the extended model, the negative effect that a decrease in country $j$ 's tax rate has on the tax base of country $i$ is even reinforced through the endogenous choice of a riskier project. A reduction of $t_{j}$ makes a risky investment more attractive for firm $i$, and the costs of failure are partly borne by firm $i$ 's home country via cross-border loss compensation. Hence the parameter range under which an increase in $\alpha$ reduces tax revenues in both countries is enlarged, relative to the benchmark case. ${ }^{22}$ Otherwise, the results from Propositions 1a and 1b carry over in full to this model extension.

\subsection{Asymmetric countries}

Our analysis has so far focused on the case of symmetric countries. This is a suitable benchmark case if one wants to find analytical solutions, but the practical implementation of a coordinated cross-border loss offset rule will almost always involve significant asymmetries between countries. In this more realistic setting it becomes impracticable, however, to derive analytical solutions for optimal tax adjustments and we therefore present some representative simulation results in the following. As before (see Table 1 ), we specify the production function of firm $i$ as $f_{i}\left(k_{i}\right)=\phi_{i} k_{i}^{0.5}$. However, we now introduce an exogenous asymmetry by allowing for differences in the productivity parameter $\phi_{i}$ between the two firms, with country 2 being the more productive location. This productivity difference could, for example, arise from differences in the quality of infrastructure in the two host countries. In particular we choose $\phi_{1}=7$ and $\phi_{2}=5$. $^{23}$

\footnotetext{
${ }^{22}$ This is seen from the fact that the restriction on the level of tax rates in Proposition $1 \mathrm{~b}$ is relaxed in this extended setting. See eq. (A.18) in the appendix.

${ }^{23}$ Recall that the production function applies to the subsidiary of firm $i$, which produces in country $j$. Hence a higher level of $\phi_{1}$ corresponds to a higher quality of infrastructure in country 2.
} 
Table 2: Cross-border loss compensation with asymmetric countries

\begin{tabular}{|c|c||cccc||cccc|}
\hline & \multicolumn{1}{|c||}{} & \multicolumn{4}{c||}{ benchmark scheme } & \multicolumn{4}{c|}{ alternative scheme } \\
\hline & $\alpha$ & $t_{1}$ & $t_{2}$ & $T_{1}$ & $T_{2}$ & $t_{1}$ & $t_{2}$ & $T_{1}$ & $T_{2}$ \\
\hline \multirow{5}{*}{$b=0.2$} & 0.0 & 0.307 & 0.350 & 1.062 & 1.555 & 0.307 & 0.350 & 1.062 & 1.555 \\
& 0.5 & 0.278 & 0.335 & 0.894 & 1.431 & 0.341 & 0.393 & 1.030 & 1.709 \\
& 0.9 & 0.230 & 0.300 & 0.661 & 1.188 & 0.389 & 0.457 & 0.965 & 1.931 \\
\hline \multirow{5}{*}{$b=0.5$} & 0.0 & 0.495 & 0.529 & 1.427 & 2.199 & 0.495 & 0.529 & 1.427 & 2.199 \\
& 0.5 & 0.473 & 0.531 & 1.351 & 2.267 & 0.565 & 0.608 & 1.502 & 2.577 \\
& 0.9 & 0.391 & 0.485 & 1.055 & 1.982 & 0.708 & 0.767 & 1.630 & 3.358 \\
\hline \hline
\end{tabular}

Notes: $\bar{G}_{1}=\bar{G}_{2}=1 ; \phi_{1}=7, \phi_{2}=5, p=0.5$

Table 2 presents our simulation results for the two different schemes of cross-border loss offset, and for either low or moderate costs of profit shifting ( $b=0.2$ and $b=0.5$, respectively). In each scenario we compare the equilibria for no cross-border loss offset $(\alpha=0)$, an intermediate level of loss offset $(\alpha=0.5)$, and the case where loss offset is almost complete $(\alpha=0.9)$.

The results in Table 2 show how the basic differences between the benchmark and the alternative loss offset scheme interact with productivity differences between countries. For the benchmark scheme, we know from Table 1 in Section 4 that tax rates will generally (though not always) fall in both countries when $\alpha$ rises. At the same time, the higher productivity of firms in country 2 leads to redistributive effects between the two countries. Since the investment by (the subsidiary of) firm 1 is higher than that of firm 2, country 1 has to grant the higher level of tax reliefs. Due to the combined effect of more aggressive tax competition and redistributive losses, country 1 always loses tax revenues when loss compensation is increased. In contrast, country 2 benefits from the increased investment of firm 1, which raises its tax base and causes country 2 to set a higher tax rate than country 1 . Increased cross-border loss compensation therefore has counteracting effects on country 2 , simultaneously leading to more aggressive tax competition and higher redistributive gains. When profit shifting costs are low $(b=$ 0.2 ), the first effect dominates and country 2's tax rate and its tax revenues fall. For higher costs of profit shifting $(b=0.5)$, however, the redistributive gains dominate for country 2. Accordingly, both its tax rate and its tax revenues rise, at least for intermediate values of cross-border loss compensation. 
Under the alternative loss offset scheme, the redistributive effects of productivity differences between the two firms work in the same way as under the benchmark scheme. However, as our theoretical analysis has shown, tax rates will always rise under the alternative scheme (Proposition 2a). Hence there are now two counteracting effects of a coordinated increase in $\alpha$ on the tax revenues in country 1 . When profit-shifting costs are low $(b=0.2)$ country 1 still loses from the expansion of cross-border loss offset, but the revenue losses are far more limited than under the benchmark loss offset scheme. When profit-shifting costs are higher $(b=0.5)$ country 1's tax revenues will even increase, as a result of less aggressive tax competition. For country 2, the revenue gains from weaker tax competition and redistributive benefits are mutually reinforcing. Hence country 2's tax revenues increase in all scenarios, implying that the revenue gains resulting from the changed investment and tax setting incentives dominate the negative mechanical effect. In sum, therefore, the superiority of the alternative loss offset scheme is maintained for revenue maximizing governments, when productivity differences between countries are taken into account.

\section{Conclusions}

In its 2005 Marks and Spencer ruling, the European Court of Justice has established the principle that the parent country of a multinational firm must allow cross-border tax relief for the losses incurred by a subsidiary in a different EU member state, if the losses incurred by the subsidiary are 'final'. Given this ruling, it is very likely that EU member states will be legally obliged to offer some form of cross-border loss offset in the coming years, even though the exact conditions under which this occurs are not yet clear. The critical question is then how to introduce cross-border loss offset in a way that minimizes the negative side effects of this change for member states' tax revenues.

In this paper we have analyzed two alternative schemes of introducing a coordinated form of cross-border loss offset. Under the first, 'benchmark' scheme, each country bases the tax rebate to loss-making subsidiaries of its domestic multinationals on its own corporate tax rate. When this scheme is applied, a coordinated increase in crossborder loss compensation reduces optimal tax rates, at least when the initial level of cross-border tax relief is already high. In an environment where tax competition is an important concern, as is the case in Europe, our analysis therefore warns that introducing cross-border loss compensation is likely to aggravate tax competition. These 
undesirable behavioral effects imply that the overall tax revenue losses accompanying the introduction of cross-border tax relief are likely to be even larger than is implied by the direct (mechanical) effect of the reform.

We also show that a simple change in the scheme of cross-border tax relief will suffice to eliminate these undesirable side effects of the reform. All that is needed is to apply the tax rate of the subsidiary's host country, rather than the parent country's home tax rate, when calculating the tax rebate. In contrast to the benchmark setting, equilibrium taxes are likely to rise under the alternative loss offset scheme when cross-border loss compensation is increased. As a consequence, tax revenue losses will be lower than is implied by the direct effect of the reform. Moreover, this scheme will comply with the legal requirement that the tax treatment of losses does not discriminate between nationally versus multinationally operating corporate groups, and it will also exhibit the efficiency-enhancing effects on firms' investment and risk-taking decisions that represents the core advantage of loss compensation. Therefore, if cross-border loss offset is to be introduced for either legal or economic reasons, our results suggest that tax rebates should be based on the tax rate in the country where the loss-making subsidiary operates.

Our analysis can be extended in several ways. A first extension would be to introduce an intertemporal model of investment and cross-border loss compensation. This would allow, for example, to distinguish between a temporary and a permanent transfer of losses from the subsidiary to the parent country, or to capture loss carryforward provisions in the host country that are limited in time. We believe, however, that adding these realistic features would not overturn the qualitative conclusions of our analysis with respect to the ranking of the alternative loss offset regimes. A second, and more fundamental, extension would be to endogenize the location decisions of multinational firms, which have been taken as given in the present analysis. In such a setting, the elasticity with which the location decision of subsidaries responds to international tax differentials should be lower under the alternative loss offset scheme, because higher tax rates would then also carry the advantage of a higher rate of loss offset. Hence we would expect that, like in the present analysis, tax competition is less aggressive under the alternative scheme than under the benchmark scheme of loss offset. A full analysis of this case must, however, be left for future research. 


\section{Appendix}

\section{The model with endogenous risk choice by firms}

To study the comparative static effects of taxes in this model, we totally differentiate the first-order conditions (2), (3) and (28) in the main text. This leads to the following equation set:

$$
\begin{gathered}
\left(1-t_{j}\right) p_{i} f_{k_{i} k_{i}} \mathrm{~d} k_{i}+\left[\left(1-t_{j}\right)\left(f_{k_{i}}-1+p_{i} f_{k_{i} p_{i}}\right)+1-\alpha t_{i}\right] \mathrm{d} p_{i} \\
+\alpha\left(1-p_{i}\right) \mathrm{d} t_{i}-p_{i}\left(f_{k_{i}}-1\right) \mathrm{d} t_{j}=0 \\
{\left[\left(1-t_{j}\right)\left(f_{k_{i}}-1+p_{i} f_{k_{i} p_{i}}\right)+1-\alpha t_{i}\right] \mathrm{d} k_{i}+\left(1-t_{j}\right)\left(2 f_{p_{i}}+p_{i} f_{p_{i} p_{i}}\right) \mathrm{d} p_{i}} \\
-\alpha k_{i} \mathrm{~d} t_{i}-\left[f\left(p_{i}, k_{i}\right)-k_{i}+p_{i} f_{p_{i}}\right] \mathrm{d} t_{j}=0 \\
\mathrm{~d} q_{i}+\frac{1}{b} \mathrm{~d} t_{i}-\frac{1}{b} \mathrm{~d} t_{j}=0
\end{gathered}
$$

In matrix notation this yields

$$
\left[\begin{array}{ccc}
\gamma_{1} & \gamma_{2} & 0 \\
\gamma_{2} & \gamma_{3} & 0 \\
0 & 0 & 1
\end{array}\right] \times\left[\begin{array}{c}
\mathrm{d} k_{i} \\
\mathrm{~d} p_{i} \\
\mathrm{~d} q_{i}
\end{array}\right]=\left[\begin{array}{c}
\gamma_{4} \\
\gamma_{5} \\
\gamma_{8}
\end{array}\right] \mathrm{d} t_{j}+\left[\begin{array}{c}
\gamma_{6} \\
\gamma_{7} \\
-\gamma_{8}
\end{array}\right] \mathrm{d} t_{i},
$$

where

$$
\begin{gathered}
\gamma_{1}=\left(1-t_{j}\right) p_{i} f_{k_{i} k_{i}}<0, \quad \gamma_{2}=\left(1-t_{j}\right)\left[f_{k_{i}}-1+p_{i} f_{k_{i} p_{i}}\right]+1-\alpha t_{i} \\
\gamma_{3}=\left(1-t_{j}\right)\left(2 f_{p_{i}}+p_{i} f_{p_{i} p_{i}}\right)<0, \quad \gamma_{4}=p_{i}\left(f_{k_{i}}-1\right) \geq 0 \\
\gamma_{5}=f\left(p_{i}, k_{i}\right)+p_{i} f_{p_{i}}-k_{i}<0, \quad \gamma_{6}=-\alpha\left(1-p_{i}\right) \leq 0 \\
\gamma_{7}=\alpha k_{i} \geq 0, \quad \gamma_{8}=1 / b>0
\end{gathered}
$$

In (A.5), the signs of $\gamma_{1}$ and $\gamma_{3}$ follow directly from the properties of the production function $f\left(k_{i}, p_{i}\right)$. The signs of $\gamma_{4}$ and $\gamma_{5}$ follow from the first-order conditions $(2)$ and (28). The signs of $\gamma_{6}$ and $\gamma_{7}$ can be unambiguously signed for $\alpha>0$ but are both equal to zero when $\alpha=0$. Moreover, $\gamma_{8}>0$ by assumption. What remains then is to sign $\gamma_{2}$. We assume in the following that the complementarity between investment and risk-taking, leading to $f_{k_{i}, p_{i}}<0$, is sufficiently strong to make $\gamma_{2}$ negative. This is a sufficient, but not a necessary condition to unambiguously sign the comparative static effects that follow. 
Applying Cramer's rule to the equation system (A.4) and using these assumptions, the effects of taxes on investment levels and risk choices in each country can be signed as:

$$
\begin{gathered}
\frac{\mathrm{d} k_{i}}{\mathrm{~d} t_{j}}=\frac{\gamma_{3} \gamma_{4}-\gamma_{2} \gamma_{5}}{\gamma_{1} \gamma_{3}-\gamma_{2}^{2}}<0 \quad \forall \quad i \in\{1,2\}, \\
\frac{\mathrm{d} p_{i}}{\mathrm{~d} t_{j}}=\frac{\gamma_{1} \gamma_{5}-\gamma_{2} \gamma_{4}}{\gamma_{1} \gamma_{3}-\gamma_{2}^{2}}>0 \quad \forall \quad i \in\{1,2\}, \\
\frac{\mathrm{d} q_{i}}{\mathrm{~d} t_{j}}=\gamma_{8}>0 \quad \forall \quad i \in\{1,2\}, \\
\frac{\mathrm{d} k_{i}}{\mathrm{~d} t_{i}}=\frac{\gamma_{3} \gamma_{6}-\gamma_{2} \gamma_{7}}{\gamma_{1} \gamma_{3}-\gamma_{2}^{2}}>0 \quad \forall \quad i, j \in\{1,2\}, i \neq j, \\
\frac{\mathrm{d} p_{i}}{\mathrm{~d} t_{i}}=\frac{\gamma_{1} \gamma_{7}-\gamma_{2} \gamma_{6}}{\gamma_{1} \gamma_{3}-\gamma_{2}^{2}}<0 \quad \forall \quad i, j \in\{1,2\}, i \neq j . \\
\frac{\mathrm{d} q_{i}}{\mathrm{~d} t_{i}}=-\gamma_{8}<0 \quad \forall \quad i \in\{1,2\}, i \neq j .
\end{gathered}
$$

Equations (A.6)-(A.11) show that an increase in country $j$ 's tax rate leads to less capital investment and less risk-taking by the subsidiary of firm $i$. In contrast, by increasing the expected tax rebate, an increase in the tax rate of the other country $i$ increases both capital investment and risk-taking by firm $i$ 's subsidiary when the loss offset parameter $\alpha$ is strictly positive. In addition to these direct effects, there are indirect effects caused by the complementarity of capital $k_{i}$ and risk-taking $\left(1-p_{i}\right)$. Under the assumptions made above, these indirect effects reinforce the direct effects.

The two governments maximize tax revenues. The tax revenues of government $i$ are:

$$
\hat{T}_{i}=t_{i}\left\{\bar{G}_{i}-\alpha\left(1-p_{i}\right) k_{i}+p_{j}\left[f\left(p_{j}, k_{j}\right)-k_{j}\right]+\left(q_{i}-q_{j}\right)\right\} \quad \forall i .
$$

Maximizing with respect to $t_{i}$ gives country $i$ 's optimal tax rate in implicit form:

$$
\begin{array}{r}
\hat{t}_{i}^{*}=\frac{\hat{B}_{i}}{-\hat{\Omega}_{i}}>0, \quad \hat{B}_{i}=\bar{G}_{i}-\alpha\left(1-p_{i}\right) k_{i}+p_{j}\left[f\left(p_{j}, k_{j}\right)-k_{j}\right]+\left(q_{i}-q_{j}\right), \\
\hat{\Omega}_{i}=\left[\gamma_{4} \frac{\mathrm{d} k_{j}}{\mathrm{~d} t_{i}}+\gamma_{5} \frac{\mathrm{d} p_{j}}{\mathrm{~d} t_{i}}+\gamma_{6} \frac{\mathrm{d} k_{i}}{\mathrm{~d} t_{i}}+\gamma_{7} \frac{\mathrm{d} p_{i}}{\mathrm{~d} t_{i}}+\frac{\mathrm{d} q_{i}}{\mathrm{~d} t_{i}}-\frac{\mathrm{d} q_{j}}{\mathrm{~d} t_{i}}\right]<0 .
\end{array}
$$

Note that endogenizing the firms' risk choice increases the sensitivity of country $i$ 's tax base with respect to its own tax rate, as compared to the benchmark model.

We can now analyze the effects of cross-border loss offset on optimal tax rates in the extended model, following eq. (9). The impact effect of a rise in $\alpha$ on investment is positive, whereas the impact effect on $p_{i}$ is negative:

$$
\frac{\partial k_{i}}{\partial \alpha}=-\frac{t_{i}\left(1-p_{i}\right)}{\gamma_{1}}>0, \quad \frac{\partial p_{i}}{\partial \alpha}=\frac{t_{j} k_{i}}{\gamma_{3}}<0 \quad \forall i .
$$


The change in country $i$ 's tax base following an increase in $\alpha$ is then given by

$$
\frac{\partial \hat{B}_{i}}{\partial \alpha}=-\left(1-p_{i}\right) k_{i}+\gamma_{4} \frac{\partial k_{j}}{\partial \alpha}+\gamma_{6} \frac{\partial k_{i}}{\partial \alpha}+\gamma_{5} \frac{\partial p_{j}}{\partial \alpha}+\gamma_{7} \frac{\partial p_{i}}{\partial \alpha}
$$

Using (10) and (A.4) to sign these effects, the interpretation of the first three effects is analogous to eq. (11). The last two effects on the right-hand side of (A.15) arise from the changes in the two firms' risk-taking behavior. The fourth effect is positive as a higher level of risk-taking by firm $j$ increases the expected tax revenues for country $i$, which does not rebate firm $j$ in case of project failure. In contrast, the fifth effect is negative as more risk-taking by firm $i$ 's subsidiary increases the expected tax rebate granted by country $i$.

As in the benchmark model, the net effect can only be signed when cross-border loss offset is almost complete $(\alpha \rightarrow 1)$ and countries are symmetric. In this case all indirect effects operating through induced changes in $k_{i}$ and $p_{i}$ cancel out, leaving only the negative direct effect of $\alpha$. In this case the tax base change thus corresponds to (12).

The effects of a change in $\alpha$ on the denominator of the optimal tax rule (A.13) are also ambiguous, in general. Differentiating (A.18) yields

$$
\begin{array}{r}
\frac{\partial \hat{\Omega}_{i}}{\partial \alpha}=\frac{\partial \gamma_{4}}{\partial \alpha} \frac{\mathrm{d} k_{j}}{\mathrm{~d} t_{i}}+\frac{\partial \gamma_{5}}{\partial \alpha} \frac{\mathrm{d} p_{j}}{\mathrm{~d} t_{i}}+\frac{\partial \gamma_{6}}{\partial \alpha} \frac{\mathrm{d} k_{i}}{\mathrm{~d} t_{i}}+\frac{\partial \gamma_{7}}{\partial \alpha} \frac{\mathrm{d} p_{i}}{\mathrm{~d} t_{i}}+\gamma_{4} \frac{\partial\left(\mathrm{d} k_{j} / \mathrm{d} t_{i}\right)}{\partial \alpha}+ \\
\gamma_{5} \frac{\partial\left(\mathrm{d} p_{j} / \mathrm{d} t_{i}\right)}{\partial \alpha}+\gamma_{6} \frac{\partial\left(\mathrm{d} k_{i} / \mathrm{d} t_{i}\right)}{\partial \alpha}+\gamma_{7} \frac{\partial\left(\mathrm{d} p_{i} / \mathrm{d} t_{i}\right)}{\partial \alpha}
\end{array}
$$

For $\alpha \rightarrow 1$, however, this expression can be unambiguously signed. Evaluating (A.16) at $\alpha=1$ and using $\left.\gamma_{4}\right|_{\alpha=1}=\left(1-p_{i}\right),\left.\gamma_{5}\right|_{\alpha=1}=-k_{i},\left.\gamma_{6}\right|_{\alpha=1}=-\left(1-p_{i}\right),\left.\gamma_{7}\right|_{\alpha=1}=k_{i}$ and the symmetry condition $t_{i}=t_{j}$ gives

$$
\begin{array}{r}
\left.\frac{\partial \hat{\Omega}_{i}}{\partial \alpha}\right|_{\alpha=1}=-\frac{4 t_{i} \gamma_{2}}{N^{2}}\left\{\left[\left(1-p_{i}\right) \gamma_{3}+k_{i} \gamma_{2}\right]+\left[k_{i} \gamma_{1}+\left(1-p_{i}\right) \gamma_{2}\right]\right\}+ \\
\frac{\left(1-p_{i}\right) \gamma_{3}+k_{i} \gamma_{2}}{N}\left[\frac{2-3 t_{j}}{1-t_{j}}\left(1-p_{i}\right)+\frac{\left(\gamma_{2}+1-t_{j}\right) t_{j} k_{i}}{\left(1-t_{j}\right) \gamma_{3}}\right]+ \\
\frac{k_{i} \gamma_{1}+\left(1-p_{i}\right) \gamma_{2}}{N}\left[\frac{2-3 t_{j}}{1-t_{j}} k_{i}+\frac{\left(\gamma_{2}+1-t_{j}\right) t_{j}\left(1-p_{i}\right)}{\left(1-t_{j}\right) \gamma_{1}}\right]
\end{array}
$$

A sufficient condition for the terms in squared brackets, and therefore for the entire derivative, to be negative is that $t_{j} \leq 2 / 3$. Hence we get:

$$
\left.\frac{\mathrm{d} \hat{\Omega}_{i}}{\mathrm{~d} \alpha}\right|_{\alpha=1}<0 \quad \Leftrightarrow \quad t \leq \frac{2}{3}
$$


Thus the elasticity of country $i$ 's tax base increases for a small increase in $\alpha$ when loss offset is almost complete and the tax rate is not too high in the initial equilibrium. In comparison to the benchmark model [eq. (13)] the range of tax rates for which this result obtains is thus enlarged, due to the endogenous risk choice of the two firms.

Lastly, we analyze the change in equilibrium tax revenues following an increase in $\alpha$. The direct effect on the tax base is given in (A.15) and has been shown to be negative for $\alpha \rightarrow 1$. For the tax externality we get

$$
\frac{\partial \hat{T}_{i}}{\partial t_{j}}=t_{i}\left[\gamma_{4} \frac{\mathrm{d} k_{j}}{\mathrm{~d} t_{j}}+\gamma_{5} \frac{\mathrm{d} p_{j}}{\mathrm{~d} t_{j}}+\gamma_{6} \frac{\mathrm{d} k_{i}}{\mathrm{~d} t_{j}}+\gamma_{7} \frac{\mathrm{d} p_{i}}{\mathrm{~d} t_{j}}+\frac{\mathrm{d} q_{i}}{\mathrm{~d} t_{j}}-\frac{\mathrm{d} q_{j}}{\mathrm{~d} t_{j}}\right]>0 .
$$

From (A.19), a rise in the foreign tax rate $t_{j}$ unambiguously raises tax revenues in country $i$. By increasing the expected reimbursement for subsidiary $j$, the tax increase will lead firm $j$ to invest more, thus augmenting the tax base of country $i$. Likewise, country $i$ 's tax base is expanded by a higher risk level chosen by the subsidiary of firm $j$, which increases expected profits. At the same time, investment and risk-taking by the subsidiary if firm $i$ are discouraged, reducing the expected tax rebates that have to be paid by country $i$ 's government. Since a rise in $\alpha$ reduces equilibrium tax rates in both countries when loss offset is almost complete, the indirect effect of a change in $\alpha$ on tax revenues is negative for $\alpha \rightarrow 1$. Hence all the qualitative results from Propositions 1a and $1 \mathrm{~b}$ carry over to an extended model where the risk-taking choices of the two MNEs are endogenized. 


\section{References}

Altshuler, R., Auerbach A.J. (1990). The significance of tax law asymmetries: An empirical investigation. Quarterly Journal of Economics 105, 61-86.

Auerbach, A.J. (2007). Why have corporate tax revenues declined? Another look. CESifo Economic Studies 53, 153-171.

Becker, J., Fuest, C. (2010). Taxing foreign profits with international mergers and acquisitions. International Economic Review 51, 171-186.

Boulogne, F., Slavnic N.S. (2012). Cross-border restructuring and "final losses". European Taxation 10-2012, 486-495.

Davies, R., Voget, J. (2008). Tax competition in an expanding European Union. Working Paper 08/30. Oxford University Centre for Business Taxation.

Devereux, M.P., Keen, M., Schiantarelli, F. (1994). Corporation tax asymmetries and investment: Evidence from U.K. panel data. Journal of Public Economics 53, 395-418.

Devereux, M.P., Lockwood, B., Redoano, M. (2008). Do countries compete over corporate tax rates? Journal of Public Economics 92, 1210-1235.

Dressler, D., Overesch, M. (2013). Investment impact of tax loss treatment - empirical insights from a panel of multinationals. International Tax and Public Finance, forthcoming.

Dwenger, N., Walch, F. (2011). Tax losses and firm investment. Evidence from tax statistics. Mimeo. Max Planck Institute Munich.

Edgerton, J. (2010). Investment incentives and corporate tax asymmetries. Journal of Public Economics 94, 936-952.

Eeckhoudt, L., Gollier, C., Schlesinger, H. (1997). The no-loss offset provisions and the attitude towards risk of a risk-neutral firm. Journal of Public Economics 65, 207-217.

Egger, P., Eggert, W., Keuschnigg, C., Winner, H. (2010). Corporate taxation, debt financing and foreign-plant ownership. European Economic Review 54, 96-107. 
European Commission (2006). Tax treatment of losses in cross-border situations. Document $\operatorname{COM}(2006)$ 824. Brussels.

European Commission (2011). Council directive on a common consolidated corporate tax base (CCCTB). Document COM(2011) 121/4. Brussels.

Eurostat (2011). Taxation trends in the European Union. Data for the EU member states, Iceland and Norway. 2011 edition. Luxembourg. http://epp.eurostat.ec.europa.eu.

Fuest, C., Hemmelgarn, T., Ramb, F. (2007). How would the introduction of an EUwide formula apportionment affect the distribution and size of the corporate tax base? An analysis based on German multinationals. International Tax and Public Finance 14, 605-626.

Gérard, M., Weiner, J. (2003). Cross-border loss offset and formulary apportionment: How do they affect multijurisdictional firm investment spending and interjurisdictional tax competition? CESifo Working Paper No. 1004. Munich.

Gérard, M., Weiner, J. (2006). Comment la compensation internationale des pertes et la répartition proportionelle des revenues imposables peuvent affecter les choix des multinationales et la concurrence fiscale, Economie et Prévision 174, 65-77.

Haufler, A., Norbäck, P.-J., Persson, L. (2012). Entrepreneurial innovations and taxation. CEPR Discussion Paper No. 9157. London.

Huizinga, H., Nicodéme, G. (2006). Foreign ownership and corporate income taxation: An empirical evaluation. European Economic Review 50, 1223-1244.

Huizinga, H., Nielsen, S.B. (1997). Capital income and profits taxation with foreign ownership of firms. Journal of International Economics 42, 149-165.

Kalamov, Z., Runkel, M. (2012). The implications of cross-border loss offset: Should the EU really implement it? Paper presented at the IIPF 2012 in Dresden.

Lang, M. (2006). The Marks and Spencer case - The open issues following the ECJ's final word. European Taxation 2-2006, 54-67.

Niemann, R., Treisch, C. (2005). Group taxation, asymmetric taxation and crossborder investment incentives in Austria. CESifo Working Paper No. 1506. Munich. 
Panteghini, P. (2001). On corporate tax asymmetries and neutrality. German Economic Review 2, 269-286.

Riedel, N., Runkel, M. (2007). Company tax reform with a water's edge. Journal of Public Economics 91, 1533-1554.

Rodrik, D. (1998). Why do more open economies have bigger governments? Journal of Political Economy 106, 997-1032.

Schindler, D., Schjelderup, G. (2012). Debt shifting and ownership structure. European Economic Review 56, 635-647.

Sørensen, P.B. (2007). Can capital income taxes survive? And should they? CESifo Economic Studies 53, 172-228. 